\title{
Pilot Abandonment Test of a Very Deep Gas Storage Salt Cavern
}

\author{
J.G. Durup, F. Vidal and C. Rolin \\ Gaz de France, Direction des Grandes Infrastructures, Département d'Expertises et de Services - Stockage, \\ 14-16, rue Touzet Gaillard, F-93486 Saint-Ouen cedex - France \\ e-mail: gerard.durup@gazdefrance.com - florence.vidal@gazdefrance.com - christian.rolin@gazdefrance.com
}

Résumé - Expérience pilote d'abandon d'une cavité saline de stockage de gaz très profonde - En raison de connaissances acquises initialement à partir d'une série d'essais in situ sur des puits et des cavités salines, réalisés vers la fin des années 80 et début 90 par Gaz de France, les enjeux relatifs à l'abandon à long terme des cavités salines ont commencé à être mieux compris. Ces expérimentations ont été réalisées en étroite collaboration avec l'École Polytechnique (France) et le Solution Mining Research Institute (USA).

L'abandon à long terme (la fermeture définitive) des cavités qui ont été creusées par dissolution dans une formation salifère, soit pour extraire du sel minéral, soit pour le stockage d'hydrocarbures ou des déchets, a été une préoccupation depuis de nombreuses années. En fait, la fermeture définitive et l'abandon des cavités salines sont plus délicats que l'abandon d'un puits pétrolier classique pour deux raisons principales :

- les puits de cavités salines sont généralement de plus gros diamètres que les puits d'exploration ou de production de pétrole ou de gaz naturel ;

- la pression du fluide en cavité augmente après la fermeture du puits.

La première différence n'est pas un frein significatif pour le bouchage efficace des puits des cavités salines. Pratiquement toute la complexité et les incertitudes associées à la fermeture et à l'abandon des cavités salines sont liées à la seconde différence - le fait que la pression du fluide en cavité croît dans le temps.

À la suite d'une brève introduction aux principes de la dissolution des cavités salines et de leur utilisation comme stockage souterrain de gaz naturel, la discussion portera sur les facteurs qui impactent la pression du fluide en cavité en cas de fermeture du puits. La deuxième partie de l'article mettra en exergue les conséquences pratiques qu'entraînent ces facteurs sur une expérimentation pilote d'abandon de cavité profonde (cavité TE02, 1500 mètres de profondeur) actuellement en cours sur le site de stockage de Tersanne, exploité par Gaz de France depuis plus de 35 années.

\footnotetext{
Abstract - Pilot Abandonment Test of a Very Deep Gas Storage Salt Cavern - As a result of knowledge gained initially from a series of succinct sealed well and cavern field tests performed in the late 1980s and early 1990s by Gaz de France (EZ58; EZ53), issues related to the long term abandonment of salt caverns became more focused. The tests were performed in cooperation with École Polytechnique (France) and were partially funded by the Solution Mining Research Institute (USA).

The long-term abandonment (sealing or plugging) of a solution-mined cavern in a salt formation that has been used for mineral production, hydrocarbon storage, or waste disposal has been a
} 
contemporary topic for many years. Sealing and abandonment of caverns in salt formations differs from sealing of an oil and gas well principally for two reasons:

- cavern wells are generally completed with much larger casings than oil and gas exploration and production wells;

- the cavern fluid pressure rises after sealing.

The first difference is not a significant deterrent to effective cavern sealing and abandonment. Essentially all of the uncertainties and complexities associated with cavern sealing and abandonment are a direct result of the second difference - the fact that the cavern fluid pressure rises through time.

After a short introduction to solution mining of salt caverns and their use as underground gas storages, the paper will first discuss the factors affecting cavern fluid pressure increase after sealing. The second part of the paper will highlight the practical impacts of these factors on a deep salt cavern abandonment experiment (Cavern TE02; 1500 meters deep), currently being performed on the natural gas storage of Tersanne operated for over 35 years by Gaz de France.

\section{INTRODUCTION}

Salt (sodium chloride) is a basic raw material in many chemical industry manufacturing processes. Salt saturated brine can be extracted by solution mining rock salt from underground salt formations (salt domes or stratified salt formations). Practically, a large diameter borehole is drilled to about 1500 meters deep, using standard oil industry drilling methods. Then a series of casings are cemented into the borehole to provide environmental protection to the surrounding sediments. And finally an injection pipe and a production pipe are lowered to the bottom of the borehole. Fresh water is pumped through the injection pipe, the salt is dissolved, and the resulting salt saturated brine is pumped to the surface through the production pipe. This mining process is termed "leaching".

In advanced leaching technologies, a pad oil material, typically "diesel" is pumped into the roof of the salt cavern that is formed by the mining process. This pad oil floats on top of the cavern brine and acts to control the mining and protect the cavern roof from developing upwards instead of outwards. Besides this active cavern shape control, significant geomechanical design work is engineered into these caverns to ensure long-term safety and stability. Once the caverns are mined out to their desired size and shape, they are converted to underground storage by a first replacement of the brine by natural gas (the "de-brining" process). From then onwards, the gas storage is operated by successive gas compression/de-pressurization cycles in response to storing or production demands. Natural gas caverns, with deep cycling of pressure, place more demands on the host salt formation than liquid caverns and this has strongly contributed to the considerable advance in the construction technology of salt caverns in the last decades.

One of the most beneficial characteristics of these underground caverns is their ability to store large quantities of hydrocarbon products. Salt caverns are essentially impermeable, meaning no fluid or gas can escape through the surrounding rock salt. This makes them ideal for storing high-pressure hydrocarbon products ranging from LPG's (Liquefied Petroleum Gasses) to Natural Gas (methane). But the storage of gaseous hydrocarbons remains the main use of salt caverns today.

Considerable research effort on the plugging and abandonment of old salt caverns has been ongoing over the past 15 years, largely organized and financially supported by the Solution Mining Research Institute Inc. [1].

\section{OVERVIEW OF THE MAIN ISSUES IN SALT CAVERN SEALING}

\subsection{Salt Creep}

When the underground rock salt formation is subjected to a stress difference (a stress difference exists when any one of the three principal stresses differs from any one of the other principal stresses), the salt deforms continuously. This viscoplastic deformation is termed "salt creep". The magnitude of the creep rate (or deformation rate) of salt depends on:

- the physical properties of the salt;

- the magnitude of the stress differences existing in the salt;

- the temperature of the salt formation.

When a cavern is created in a salt formation, stress differences develop and the salt surrounding the cavern begins to creep (or flow) into the opening. Creep will continue until the cavern volume vanishes. Salt creep into a cavern will indeed continue indefinitely unless the stresses that were removed (when the cavern was created) are replaced. This could only happen if a material with the same physical properties and temperature is placed into the cavern and the salt surrounding the cavern is allowed to creep around the material placed in the cavern so as to remove all void space. But for practical and economical reasons, the filling material is generally saturated brine. 
As the salt surrounding the cavern flows toward and into the cavern, the fluid in a sealed cavern is compressed causing the cavern pressure to increase. Since the rate at which the salt flows or creeps into the cavern depends on the difference between the cavern fluid pressure and a measure of the salt stress, the rate of cavern creep slows as the cavern fluid pressure increases. Stationary creep can be described by NortonHoff's constitutive law (more details in Section 3.4), whose uniaxial formulation is:

$$
\dot{\varepsilon}=A^{\prime} \exp \left(-\frac{Q}{R T}\right) \sigma^{n}
$$

In the case of a spherical cavern (the exact shape of a cavern is not spherical, but this approximation holds for rough estimations) the stationary volume loss rate can be written:

$$
\dot{V} / V=-A^{\prime} \exp \left(-\frac{Q}{R T_{\infty}}\right) \frac{3}{2}\left[\frac{3}{2 n}\left(P \infty-P_{c}\right)\right]^{n}
$$

where $P_{\infty}$ is the geostatic pressure, $P_{c}$ is the cavern pressure and $T_{\infty}$ the geothermal temperature at cavern average depth.

Figure 1 shows computations of a typical cavern fluid pressure response after a cavern is merely shut-in for instance after a leaching phase (or sealed). Of course, the pressure rise observed in an actual shut-in cavern well is the result not just of salt creep, but also the other factors described below. Pressure rise measurements on the field correspond essentially to the added effects of thermal expansion and creep (computed forecast in full line in the figure). This specific diagram shows two field measurements (down-hole pressure logs) matching quite satisfactorily with a pressure forecast curve; other cases with more frequent field points also confirm this statement.

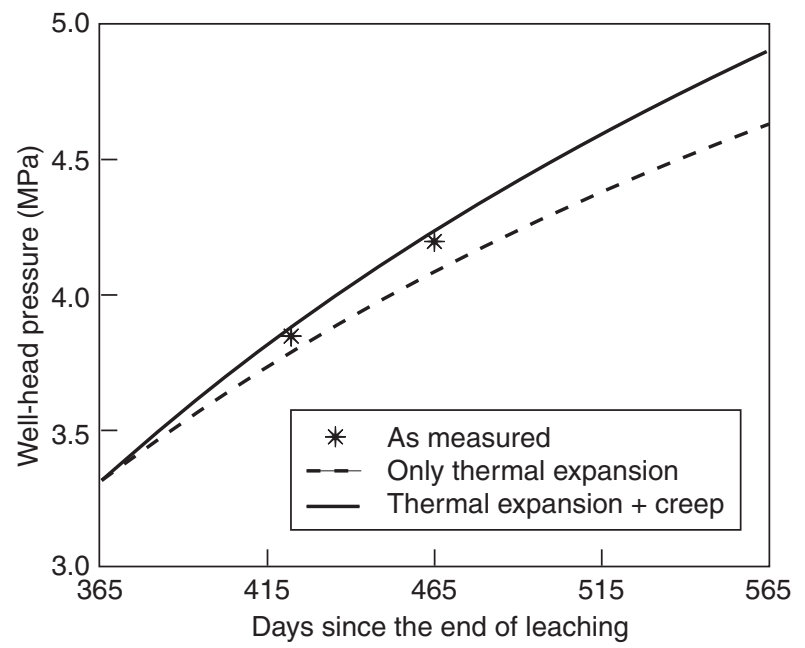

Figure 1

Pressure rise computations for Etrez cavern field, France.

\subsection{Salt Massif/Cavern Fluid Heat Transfer}

Solution mining of a salt cavern results in a significant disruption of the thermal environment in the salt formation. The raw water injected into the formation to leach out a cavern is almost always much cooler than the salt formation. Continual leaching of a cavern to its final shape can result in a significant cooling of the salt formation surrounding the cavern, particularly near the cavern boundary. Unless a cavern has been inactive for a long period of time (several years), the fluid in the cavern will be at a much lower temperature than the "pre-cavern" temperature of the rock salt. The time required for the fluid in a salt cavern to reach a "steadystate" (far field) temperature depends of course on the temperature difference, but also to a large extent on the size of the cavern.

Figure 2 illustrates a typical temperature increase of the brine in an inactive salt cavern. Here almost $75 \%$ of initial geothermal temperature is reached in a small $8000 \mathrm{~m}^{3}$ cavern after one year. Temperature monitoring on the field (temperature logs) show that a good match can be obtained between measurements and computations.

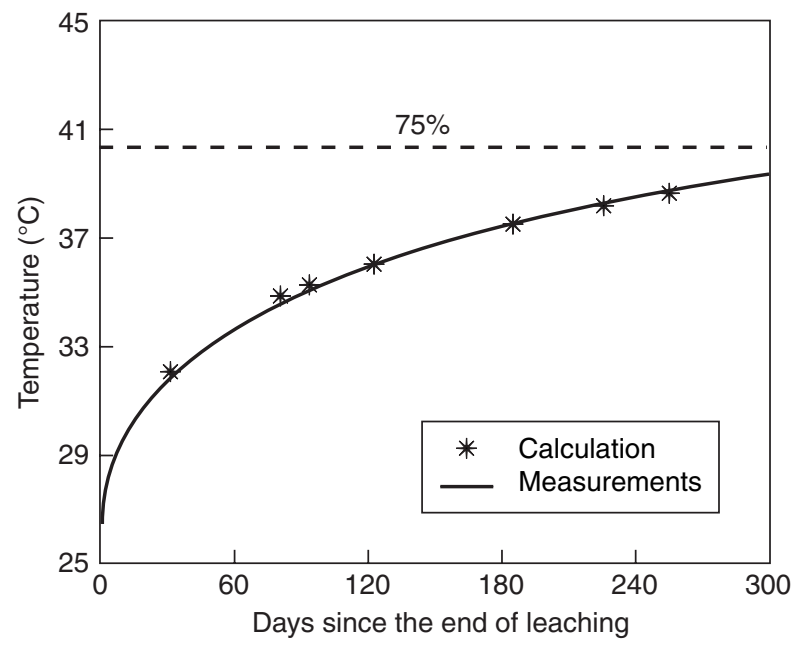

Figure 2

Brine warming computations for Etrez cavern field, France.

Thus, when the cavern is sealed, heat will flow from the salt formation to the cavern fluid and the cavern fluid temperature will rise. The temperature rise in the fluid will result in an expansion of the fluid and if the cavern is sealed, the cavern fluid pressure will increase. This temperature rise is perhaps the most significant factor in producing an increase in the sealed cavern fluid pressure. However, this pressure increase is one of the least difficult to mitigate. 
Thermal expansion effects can then easily be computed; if $\dot{T}$ is the temperature increase rate, then the contribution of thermal expansion to pressure build up rate is:

$$
\dot{P}=\frac{\alpha}{\beta} \dot{T}
$$

where the parameters are approximately $\alpha=4.4 \cdot 10^{-4}{ }^{\circ} \mathrm{C}^{-1}$ and $\beta=4 \cdot 10^{-4} \mathrm{MPa}^{-1}$ for a spherical cavern. Hence, a $1^{\circ} \mathrm{C}$ temperature increase in a closed cavern leads to a $1.1 \mathrm{MPa}$ pressure build up.

\subsection{Salt Dissolution}

Again, unless a cavern has been idle for a long time, the cavern fluid will not be $100 \%$ saturated with sodium chloride. After the cavern is sealed, dissolution will continue as the saturation approaches $100 \%$ and as the temperature of the cavern fluid rises. Salt dissolution results in an increase in the cavern volume, which will decrease the cavern fluid pressure. For example, if fresh water is injected in a salt cavern, the cavern volume will eventually increase by about $15 \%$ beyond the volume of injected fresh water as the water becomes saturated. This cavern volume increase will consequently produce an associated pressure decrease.

Furthermore, the salt dissolution process itself is an endothermic chemical reaction. This endothermic reaction will reduce the temperature of the cavern fluid (brine), which further decreases the cavern fluid (brine) pressure.

\subsection{Brine Transport from the Cavern into the Salt Formation}

Any brine transported from the cavern to the surrounding salt formation will decrease the volume of fluid in the cavern, and thus, the pressure in the cavern fluid. The nature of the cavern fluid transport from the cavern to the salt formation is perhaps the most significant and technically controversial issue in cavern sealing and abandonment. It is difficult to comprehend fluid pressures within the salt matrix when we normally think of salt as impermeable. Yet, penetration of cavern brine into the salt formation will result in fluid pressures in the salt matrix which will in turn impact the salt matrix stresses, the creep of the salt, the salt micro-permeability, and in turn, the cavern fluid pressure. This complex situation has been a major challenge in the SMRI Cavern Sealing \& Abandonment Research Program [1].

As the cavern fluid pressure increases in a cavern, eventually a fluid pressure distribution will be approached in which the cavern fluid pressure in the upper part of the cavern exceeds the maximum (least-compressive) stress in the salt behind the cavern wall. Similarly, in the lower part of the cavern, the brine pressure will be less than the maximum (least-compressive) principal stress in the salt surrounding the cavern behind the cavern wall. This condition will necessarily occur simply because of the density contrast between salt and the cavern fluid. The vertical pressure gradient in the brine must be consistent with the brine density, which is markedly less than (about one-half) the density of salt. Thus, a pressure difference will always exist (at least over a portion of the cavern surface) between the cavern fluid and the salt formation.

Some cavern fluid will always permeate the salt in the cavern wall both before and after cavern sealing (unless the cavern fluid pressure is less than the pore pressure in the surrounding salt). Before the cavern is sealed, the amount of cavern fluid that permeates the salt cavern walls is negligible. After the cavern is sealed and the cavern fluid pressure increases, the amount of cavern fluid permeating the cavern wall increases both because the pressure gradient (driving the fluid transport) increases and because the salt permeability may increase.

Figure 3 illustrates increasing amounts of cavern fluid (brine flow-rate) permeating in the salt formation as a function of imposed increasing pressure gradients in the cavern. This relationship between the pressures and the flow-rates has served to evaluate a "global micro-permeability" $K$ for this specific rock-salt massif.

Brine percolation across the cavern wall can be evaluated by supposing that the cavern behaves like a spherical cavern, of radius $R$ such that $V=4 \pi R^{3} / 3$, that is in a porous medium and that globally percolation obeys Darcy's law. During steady state, the brine flow rate across the cavern wall can be expressed as :

$$
\dot{\varepsilon}_{\text {perc }}=\frac{Q}{V}=-3 K \frac{P_{c}-P_{0}}{\eta R^{2}}
$$

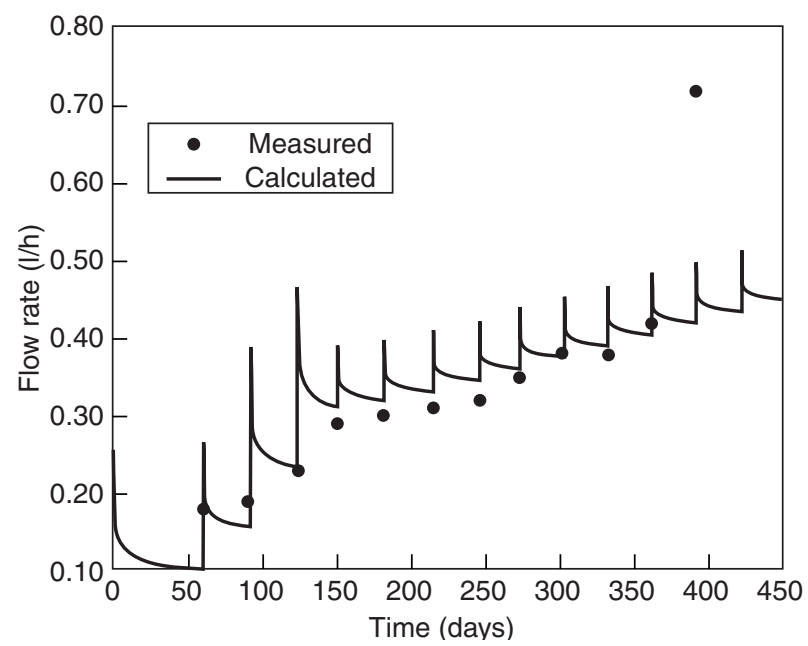

Figure 3

Brine percolation in a salt formation (after [3], EZ58 Experiment). 
where $K$ is salt global micro-permeability (typically between $10^{-22} \mathrm{~m}^{2}$ and $\left.10^{-19} \mathrm{~m}^{2}\right), P_{c}$ the brine pressure in the cavern, $P_{o}$ the natural pore pressure in the salt massif, $R$ the cavern radius, and $\mathrm{h}$ the cinematic viscosity of the brine (typically $1.2 \cdot 10^{-3}$ Pa.s at $45^{\circ} \mathrm{C}$ and diminishing with temperature). $P_{o}$ corresponds to the halmostatic pressure which supposes that there is no brine flow through the cavern wall when the later is open to the atmosphere at the surface; this has been observed on the field [3].

If the cavern fluid pressure cannot be reduced sufficiently through the diffusional flow (permeation) described above, it is conceptually possible that a salt fracture or fractures could develop, which in turn, would reduce the cavern fluid pressure. Whether or not a fracture or fractures develop depends on the rate of cavern fluid pressurization. Low pressurization rates are not expected to result in fracturing of the salt, some brine permeating the salt will limit the eventual brine pressure rise in the cavern. On the contrary, very high rates of pressurization might well produce a fracture. High rates of sealed cavern fluid pressure increases are generally the result of cavern fluid thermal expansion. Thus if the cavern fluid thermal expansion can be mitigated, for example by a waiting time to allow cavern temperature to approach equilibrium, then the risk of salt fracture will be either significantly reduced or completely avoided.

\subsection{Brine Transport from the Cavern at the Casing Shoe}

Cavern fluid pressure decreases resulting from cavern fluid transport out of the cavern at the sealing plug/casing shoe are similar to cavern fluid pressure decreases resulting from cavern fluid transport into the walls of the cavern.

Diffusional flow (permeation) can occur through the sealing cement plug and the cement between the salt borehole wall and the deepest casing. Additionally, pressure decreases can conceptually occur from fluid transport that produces and results from fracturing of the salt/cement or the cement/casing interfaces.

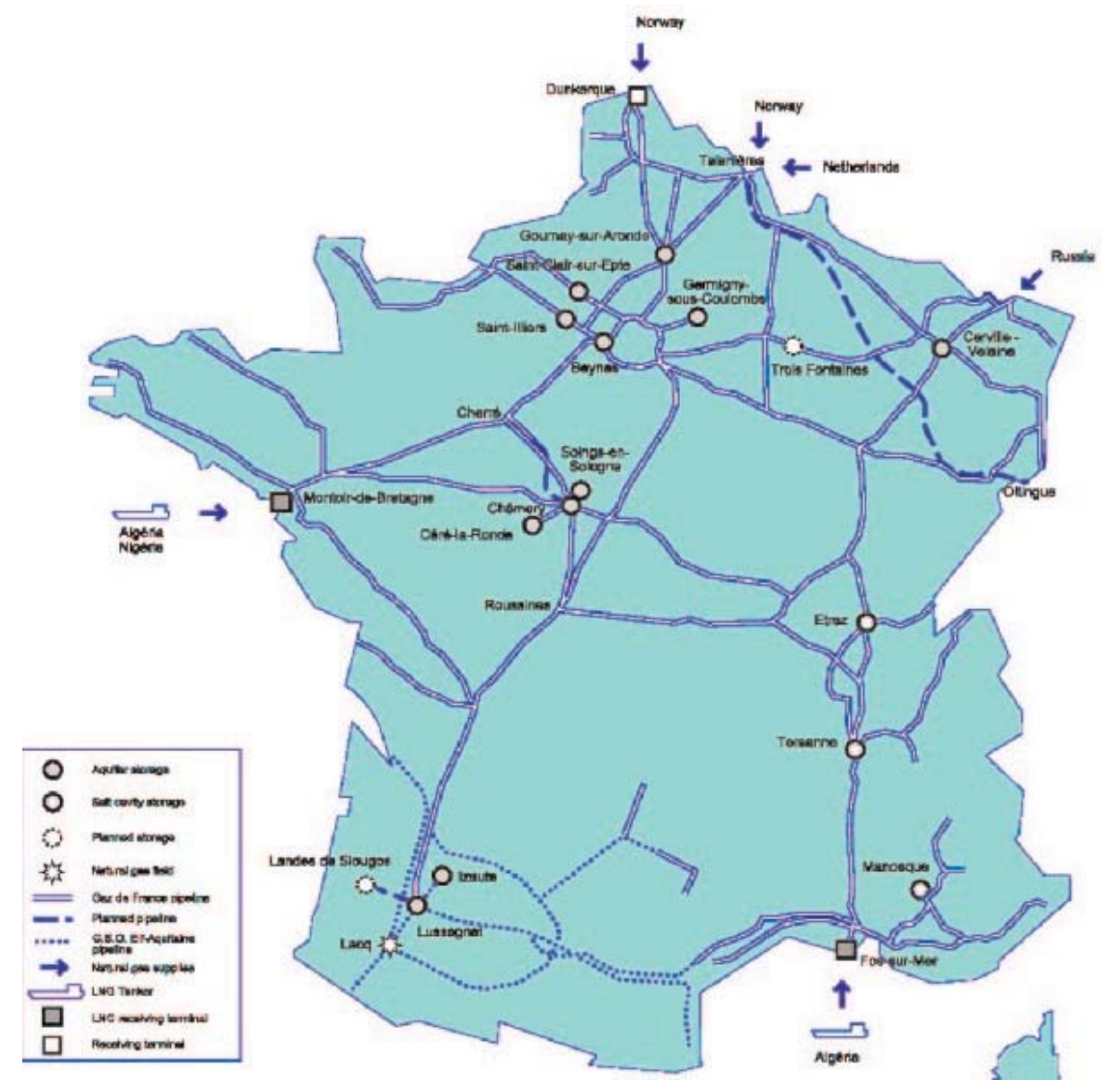

Figure 4

Tersanne natural gas storage. 


\subsection{Coupled Processes}

The processes discussed above are interconnected or "coupled". Some of the couplings are "one-way couplings" while others are "two-way couplings".

For example, brine temperature change results in brine pressure change. However, brine pressure change does not cause significant brine temperature change. This is a one-way coupling.

On the other hand, salt creep causes brine pressure change and brine pressure change impacts salt creep. This is a twoway coupling. Because of this complex coupling, a comprehensive understanding of the sealed cavern stress states and potential fluid (brine) transport is only possible through sophisticated numerical modelling.

On this basis, Gaz de France financed the development (with Brouard Consulting) of the specific modelling tool LOSAC ${ }^{\odot}$ dedicated for the abandonment of salt caverns. This is the code used to interpret and predict down-hole cavern behaviour in the TE02 pilot abandonment experiment.

\section{TERSANNE STORAGE FACILITY AND THE TE02 PILOT TEST}

\subsection{Short Overview of the Tersanne Cavern Storage Facility}

Figure 4 shows Tersanne storage in south-east France, between two other cavern storages operated by Gaz de France: Etrez just northwards and Manosque just southwards. Tersanne was GDF's first cavern storage facility, with 14 caverns developed (1968-1986). All the caverns, were in operation early 2004. Cavern TE02 developed from November 1968 to February 1970 was GDF's very first natural gas storage cavern. Its initial geometrical volume was $100000 \mathrm{~m}^{3}$ but after 35 years of operation, $60 \%$ of this volume was lost by salt creep. Cavern geometrical volumes were more than doubled for the following Tersanne caverns.

Tersanne salt caverns were developed in a 200 meter thick halite formation between 1350 and 1550 meters below surface. The rock-salt is very pure with only a few percent of dispersed clayey and anhydrite insolubles. The last casing shoe is typically 25 meters below top of salt, cavern neck is about 15 meters high and the cavern itself about 100 meters high. The average cavern spacing of about 300 meters integrates topographical constraints, but gives a globally hexagonal cavern network. Except for TE01 and TE02, each Tersanne cavern had an average initial cavern storage space of $200000 \mathrm{~m}^{3}$.

\subsection{Conceptual Approach to the TEO2 Abandonment Test}

As a result of knowledge gained from a series of succinct sealed well and cavern field tests performed in the late 1980s and early 1990s by Gaz de France, much of the issues discussed above and related to the long term abandonment of salt caverns became more focused $[2,8]$. The tests were performed in cooperation with École polytechnique (France) and were partially funded by the Solution Mining Research Institute (SMRI Inc., USA).

A largely accepted salt cavern abandonment concept has been proposed to the industry through the SMRI [11]. Basically, this concept states that provided:

- the salt formation has adequate permeability properties;

- that cavern brine thermal expansion is mitigated by a waiting time allowing cavern temperature to approach equilibrium, then cavern brine pressure will reach an equilibrium pressure reflecting the equalizing effects of brine permeation and salt creep.

The primary objective of the TE02 pilot abandonment project is to verify this concept for a relatively deep gas cavern (about 1500 meters deep) where thermal and mechanical conditions are very specific. Indeed, even if similar tests have been initiated, all have up to now addressed relatively shallow salt caverns (less than 500 meters deep). This is the first case where the concept is experimented on a deep natural gas storage cavern.

The second part of this paper will discuss about how some of these factors discussed above are being considered in the ongoing TE02 test programme (current 2005).

Figure 5 shows two distinct forecasts of the very long term (300 years) pressure evolution after:

- temperature effects are mitigated,

- the salt cavern is sealed.

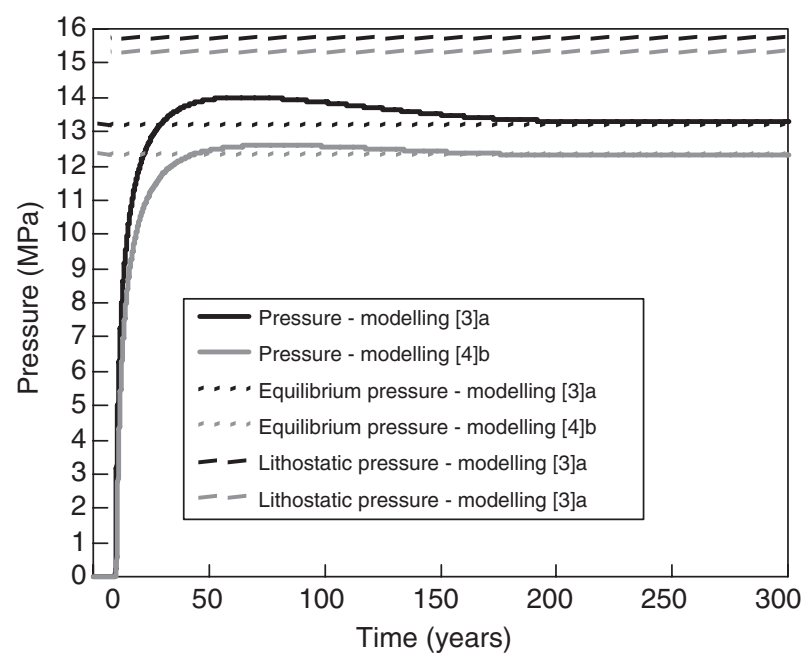

Figure 5

Preliminary forecasts of the long term pressure evolution after sealing TE02 cavern. 


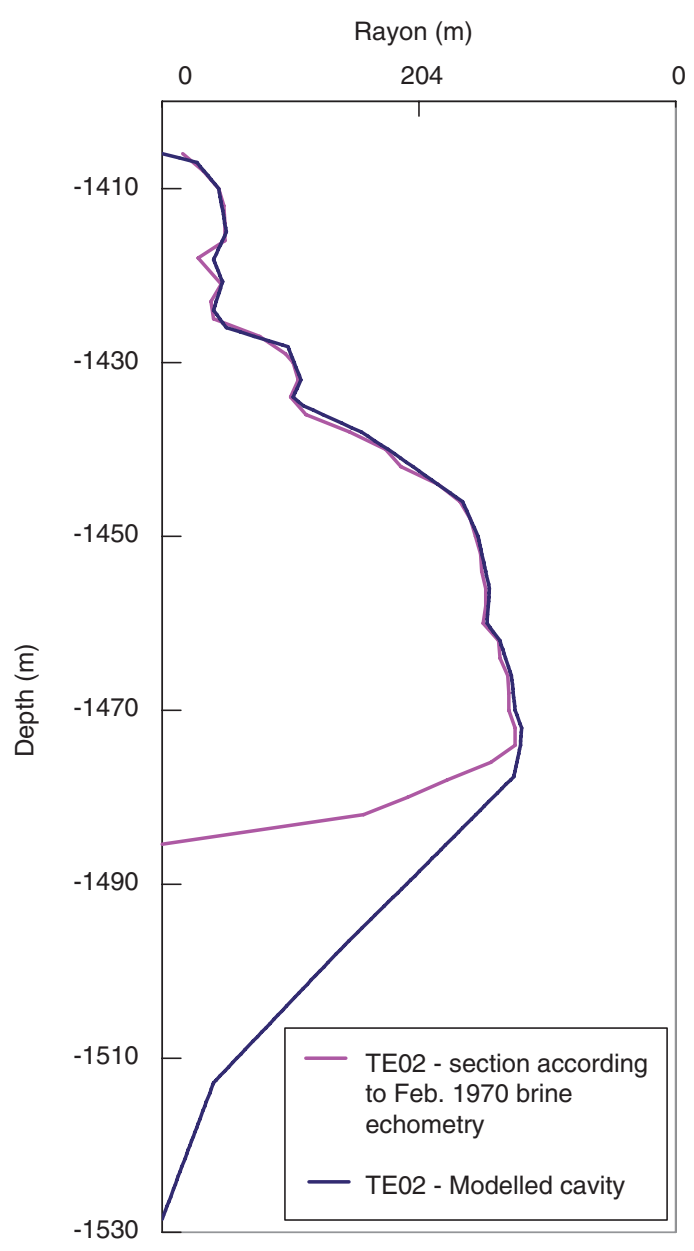

Figure 6

TE02 initial cavern shape (1970).

$1376 \mathrm{~m}$ : Top of stratified salt formation (Tertiary - Oligocene). $1392 \mathrm{~m}$ : Last casing shoe (9',5/8 cemented casing). $1406 \mathrm{~m}$ : Top of cavern i.e. cavern neck height of 13 meters. $1485 \mathrm{~m}$ : Top of insoluble sump i.e. the cavern floor. 1530 m: Maximum depth of e sump (initial borehole TD).

Pressures are calculated at well head for practical experimental reasons, but the real permanent sealing, will be ensured by realizing cement plugs at the casing shoe and at different depth intervals in the well. Consequently, the anticipated well head pressure will be nil.

Both curves anticipate long term equilibrium pressure to be over $2 \mathrm{MPa}$ below lithostatic pressure, hence clearly highlighting that any risk of fracturation is well avoided. The slight pressure rise above equilibrium pressure over the first hundred years corresponds to residual temperature effects.

The principal objective of the TE02 experiment will be to collect sufficient data over several years in order to improve the reliability of the final forecast.

\section{SOME CAVERN SEALING ISSUES IN THE TE02 PROJECT}

\subsection{Re-Brining and Salt Dissolution Concerns}

Figure 6 shows that the initial cavern diameter of cavern TE02 was $56 \mathrm{~m}$ for a cavern volume of about $100000 \mathrm{~m}^{3}$ (coloured line) The cone-shaped roof is for mechanical stability. The double-coned "global envelope" (black line) comprising both the storage space and the insoluble sump (the total excavated space) is the pertinent input shape for geomechanical assessments. Approximately $40000 \mathrm{~m}^{3}$ of water were needed to re-fill TE02 cavern, confirming that about $60 \%$ of the initial cavern volume has been lost by salt creep over the past 35 years of operation (1970-2005). From past experience, this value of almost $2 \%$ volume loss per year is quite typical of Tersanne caverns.

The very first task performed in this pilot test was to remove the natural gas from the cavern and to have it refilled with saturated brine ("re-brining"). This operation started in April 2005 with the replacement of the natural gas pushed out of the cavern by fresh water injected at the bottom of the cavern; this operation lasted 35 days. Less than two months later, by end of June, the water had naturally turned into saturated brine (about $320 \mathrm{~g} / \mathrm{L}$ ) and this saturation process was carefully monitored by regularly sampling brine from the cavern (7 samples over the re-brining period), and measuring its density.

This saturation process implied some salt dissolution at the cavern walls, increasing the cavern volume by about $15 \%$ and subsequently modifying the cavern shape. The water was injected at the bottom of the cavern through a brine tubing and $G D F$ calculated precisely this dissolution process with a specific in-house software called RESAUM. This software determines in real time the depth of the gas/brine interface, which was deliberately maintained below the last casing shoe as long as complete saturation of the brine was not reached, in order to reduce any potential risk of uncontrolled dissolution at the casing shoe. Ultimately however, the last casing shoe was also drowned, all the remaining gas was removed, and the bore-hole was completely filled up with brine all up to the surface (July 2005).

The gas completion will be removed in 2006 and a sonar survey will be run for detailed data on the cavern shape (and volume). Additionally, the last casing and its cementation will be controlled (Corrosion and Cement Bond logs). The cavern will be equipped with a permanent logging cable for continuous temperature profile and down-hole pressure monitoring; these are crucial input parameters for the LOSAC software. Well-head pressures will be also continuously monitored and any bleeding of brine to reduce cavern pressure is being precisely measured and interpreted in terms of creep and compressibility. 


\subsection{Cavern Compressibility}

A standard value of the cavern intrinsic compressibility factor for Tersanne caverns is $\beta=4 \cdot 10^{-4} \mathrm{MPa}^{-1}$ (Boucly, 1982). Very first estimations of the apparent compressibility $\beta$ ' of TE02 were performed during early stage brine bleedings of brine (September 2005) from the cavern, and this parameter, which is just a ratio of $\mathrm{d} V / \mathrm{d} P$, was found to be approximately $50 \mathrm{~m}^{3}$ per MPa of pressure decompression. This value corresponds to a $\beta$ which is significantly larger than the standard value indicated above, as shown in:

$$
\mathrm{d} V=\beta V \mathrm{~d} P
$$

From TE02 cavern volume of $\mathrm{V} \approx 40000 \mathrm{~m}^{3}$ can be derived $\beta=12.5 \cdot 10^{-4} \mathrm{MPa}^{-1}$ which is clearly over three times the standard value. Such discrepancies have already been observed either when cavern shape is flat (or "pennyshaped"), or when the cavern shows wall surfaces with "pockets" liable to trap gas during the re-brining [11]. Figure 5 shows that TE02 cavern shape has neither of these particularities. Rather, our opinion is that these preliminary measurements were performed at such an early stage after the re-brining process that there was still substantial dissolved natural gas in the brine. In time and with subsequent bleedings and evacuation of dissolved gas, TE02 cavern compressibility values are expected to decrease and approach standard values.

Regular cavern compressibility measurements are scheduled in the test programme.

\subsection{Temperature Effects}

Immediately after TE02 was re-filled with brine, the most active factor in the salt cavern was brine warming (creep and brine percolation can be neglected at this early stage). This temperature rise induces a brine thermal expansion $\dot{\varepsilon}=\alpha \dot{T}_{i}$ ( $T_{i}$ being the brine temperature). If TE02 was at this stage permanently closed at well-head, the expansion would be prevented and consequently brine pressure would increase $\dot{\varepsilon}=\beta \dot{P}_{i}$ which means that $\dot{P}_{i}=(\alpha / \beta) \dot{T}_{i}$. For a thermal expansion coefficient of saturated brine of $\alpha=4.4 \cdot 10^{-4}{ }^{\circ} \mathrm{C}^{-1}$, and a standard intrinsic compressibility factor $\beta=4 \cdot 10^{-4} \mathrm{MPa}^{-1}$, this means that a one ${ }^{\circ} \mathrm{C}$ increase in temperature generates about one MPa increase in pressure. Now this clearly highlights the need to have precise evaluations of two factors:

- the temperature evolution inside TE02 cavern;

- the compressibility factor for TE02 cavern.

Temperature effects in TE02 was first evaluated for an average reference cavern depth of $1468 \mathrm{~m}$ ( $c f$. Fig. in 4.1). At this depth, and considering an average geothermal gradient at Tersanne of $A=0.0363^{\circ} \mathrm{C} / \mathrm{m}$, the initial salt massif temperature is $68^{\circ} \mathrm{C}$. But since the water used to re-fill TE02 was only at about $15^{\circ} \mathrm{C}$, the temperature gap was potentially $53^{\circ} \mathrm{C}$. Cavern temperature is relatively uniform with depth due to brine mixing by thermo-convection. Therefore, there existed a potential pressure increase of $53 \mathrm{MPa}$ if the cavern was permanently sealed right away. Added to the cavern brine pressure (halmostatic pressure) of $18 \mathrm{MPa}$ at the reference depth, the total cavern pressure of $71 \mathrm{MPa}$ would largely exceed the fracturing pressure at the cavern walls, especially at the weakest point, which is at casing shoe $(1392 \mathrm{~m})$ where the lithostatic pressure is only about $30 \mathrm{MPa}$. To avoid this situation "steady state" temperature must be approached, and to achieve this, three options have been considered:

- warm the water before injection, but the cost being probably prohibitive;

- leave some gas to increase compressibility b, but with some technical difficulties;

- allow the brine temperature to rise naturally, but knowing that this is a slow process.

It is this last option which has been chosen in this abandonment pilot test. Practically that means a waiting phase of several years will be observed until the cavern temperature has "sufficiently" approached equilibrium with the rock massif. During this observation phase, measurements will include cavern temperature profiles (permanent laser logging method), creep evolution (pressure increase data), and compressibility values (pressure relief data). These data will serve as input in GDF's specific cavern abandonment tool LOSAC to forecast a reliable date for the final cavern sealing.

In Figure 7, preliminary TE02 temperature computations show that the brine steady state temperature of $\approx 68^{\circ} \mathrm{C}$ will only be reached after several decades. However, over $75 \%$ of this final temperature can be reached in about 4 years. While the injected water temperature at well-head was only $15^{\circ} \mathrm{C}$ (April 2005), in situ measurements indicated that the temperature was already $35^{\circ} \mathrm{C}$ by June 2005 , clearly confirming the steep transient rise at the beginning of the curve.

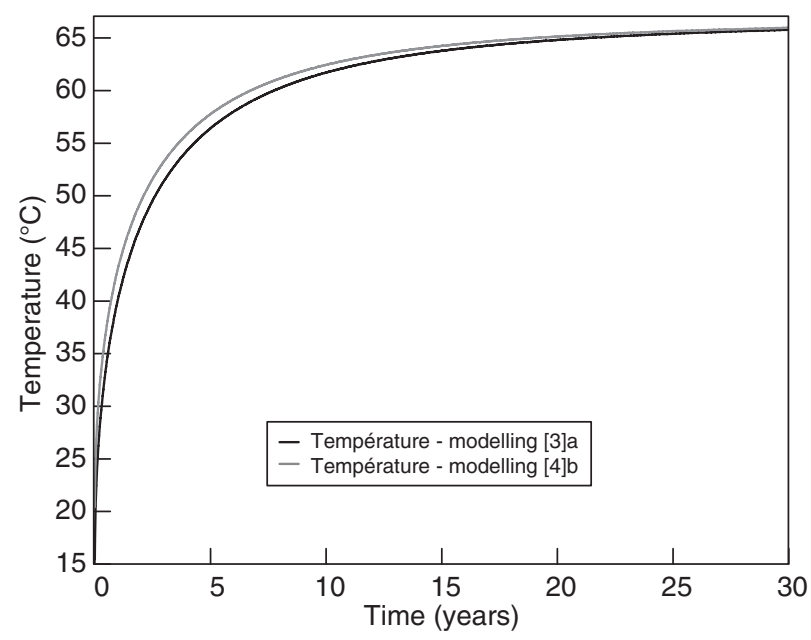

Figure 7

TE02 temperature evolution. 
From the end of the re-brining process (July 2005) and the anticipated date of removal of the gas completion (end of 2006), the cavern brine is therefore essentially in its transient thermal expansion phase. As this would induce extremely sharp pressure rises and operational constraints (regular bleed-offs), the well is not closed. Instead, the brine volume resulting from thermal expansion is allowed to be expelled freely at well-head; and the corresponding brine production rate is being carefully monitored.

Over the first four months, from August to November 2005, the brine production rate has decreased approximately from 4 to $3 \mathrm{~m}^{3} /$ day. During this transient stage, brine production rates are still relatively unstable but they are expected to decrease regularly since the rate of cavern temperature rise will decrease in time as anticipated in Figure 6. The measured brine production rates will firstly be corrected to account for non-thermal effects (creep, salt dissolution, etc.) and then they will be matched with the anticipated calculated brine rate evolution solely due to thermal expansion.

\subsection{Salt Creep Influence}

The salt creep described in Section 2.1 will need to be determined for TE02, essentially because it is a major component, with thermal expansion, of the brine expelled out of the cavern (if the well-head is left open, as during the transient period), or of cavern pressure rise (if the well-head is temporarily shut, as planned for later more stabilized periods). For its creep rate computations, the LOSAC software requires the mechanical parameters of a steady-state behaviour law, sometimes called the Norton-Hoff constitutive (or power) law:

$$
\dot{\varepsilon}=A \exp \left(-\frac{Q}{R T}\right) \sigma^{n}
$$

where $A, n$ and $Q / R$ are three parameters, $s$ is the applied uniaxial stress, and $T$ is the (absolute) rock-salt temperature. Fitting of Tersanne rock-salt laboratory data to this constitutive law yielded an exponent $n$ close to 3 , and $Q / R$ values ranging from 4100 to $6600 \mathrm{~K}$ which are all quite typical values.

This behaviour law for rock-salt is characterized by a constant strain generated, by a constant stress (after a transient phase), with a highly non-linear stress influence on the strain rates. Additionally, there is no visco-plastic stress threshold nor any strain hardening. This law is well adapted for salt cavern abandonment because the issue is the very long term behaviour (maybe centuries) of a salt cavern submitted to a relatively simple pressure scenario of the cavern brine pressure (either slightly increasing or at equilibrium if the abandonment concept is verified). In fact, during salt creep tests under uniform stress, experience shows that after only some months, strain rates clearly stabilize.
If there is very little brine percolation out of the cavern, cavern pressure will rapidly approach equilibrium with the geostatic pressure and this law will efficiently express this kinetic. On the other hand, if percolation is more active, the law will tend to indicate an unchanged equilibrium pressure as long as cavern volume has not decreased substantially, which is a slight drawback of this law. In fact, the mechanical behaviour of rock-salt under extremely low stresses (as will be the case on the long term in a closed abandoned cavern) remains difficult to study, even in laboratory.

\subsection{Available Data to Evaluate Brine Permeation}

Gaz de France has regularly performed brine tightness tests on all the Tersanne wells (1968-1980), just after the drilling of each well, when there was only the borehole (simple geometry) i.e. before leaching begins. The basic principle of these tests is to apply a constant brine pressure levels on the rock-salt, and to measure the corresponding steady-state brine percolation rates in the rock-salt massif. The value of the brine percolation rate validates (or not) the tightness at the corresponding pressure level, for the rock-salt massif and the cementation of the last casing shoe.

The results of these Tersanne tightness tests have been interpreted in terms of global in-situ micro-permeability of the rock-salt [11]. The interpretation was carried out in two steps. Firstly, the measured "apparent percolation rates" were corrected by taking into account such effects as transient permeation, temperature, transient creep, salt dissolution, compressibility, etc. Secondly, the "corrected" steady-state percolation rate was back-calculated using assumptions on porosity, pore compressibility, and an "equivalent" global micro-permeability $K$. The average $K$ value for Tersanne rock-salt was $2 \cdot 10^{-21} \mathrm{~m}^{2}$.

\section{CONCLUSIONS}

This paper provides an overview of the conceptual approach Gaz de France intends to apply for the long term abandonment its deep salt caverns (currently operated as compressed natural gas storages). It involves a complex combination of several physical processes and further research effort is required to improve the understanding of their effects on a specific cavern site. Consequently, Gaz de France has initiated a real-scale pilot abandonment test on TE02, the oldest cavern at the Tersanne gas storage facility.

In 2006, preparatory work for the test is ongoing : the cavern has been re-brined in 2005, gas completion removal is scheduled for 2006, and the cavern will be equipped with down-hole $P \& T$ monitoring devices. The cavern will remain several years under observation while allowing for sufficient temperature build-up of the brine. All the data collected will serve as input for LOSAC, an in-house software specifically developed for salt cavern long term abandonment computations. 
The basic objective of this test is to demonstrate that pressure build-up in a closed Tersanne salt cavern does not reach geostatic values (no fracturing) but, rather, due to the combined effects of salt creep and salt (micro) permeability, will vanish when a steady-state value of cavern pressure, significantly lower than geostatic pressure, is reached.

Determining the appropriate and reliable date for the safe, environmentally friendly and definitive long-term closure of this specific salt cavern well will be the major result of the experiment.

\section{REFERENCES}

1 Ratigan, J. (2003) The Solution Mining Research Institute Cavern Sealing and Abandonment Program 1996-2002, Proc. SMRI Spring Meeting 2003, Houston.

2 Durup, J.G. (1991) Long-term Permeability Field-test in Rock salt, Proc. International Congress on Rock Mechanics, Aachen.

3 Durup, J.G. (1994) Long-term tests for Tightness Evaluations with Brine and Gas in Salt, Proc. of the Solution Mining Research Institute, Fall Meeting 1994, Hannover.

4 Fokker, P.A. (1995) The Behaviour of Salt and Salt caverns, Thesis Dissertation, Delft University of Technology, Netherlands.
5 Bérest, P., Brouard, B., Durup, J.G. (1996) Behavior of sealed solution-mined caverns, Proc. 4th Conf. Mech. Beh. Of Salt, Montreal, Trans Tech Pub., Clausthal-Zellerfeld, Germany, 1997.

6 Wallner, M., Paar, W.A. (1997) Risks of Progressive Pressure build up in a Sealed cavern, Proc. of the Solution Mining Research Institute, Fall Meeting 1997, El Paso.

7 Berest, P., Brouard, B., Durup, J.G. (1997) Abandonment of Salt caverns, Rev. Fr. Géotech. (in French).

8 Brouard B. (1998) On Salt cavern Behavior (in french), Ph.D. Thesis, École polytechnique, France.

9 Berest, P., Bergues, J., Brouard, B.,. DeGreef, V., Le Bras, Y., Durup, J.G., Guerber, B. (1998) Long-Term Evolution of a Sealed Cavern, SMRI Research Project No. 98-0004, prepared for the Solution Mining Research Institute by LMS École Polytechnique and Gaz de France, France.

10 Berest, P., Brouard, B., Durup, J.G., Bergues, J., Guerber, B. (2000) A Salt-Cavern Abandonment Test, Int. J. Rock Mech. Min.

11 Brouard, B., Bérest, P., Durup, J.G. (2001) In situ salt permeability testing, Proc. of the Solution Mining Research Institute, Fall Meeting 2001, Albuquerque.

12 Brouard, B., Durup, J.G., Berest, P. (2002) A First Salt cavern Abandonment Software, Proc. of the Solution Mining Research Institute, Spring Meeting 2002, Banff.

Final manuscript received in February 2006 